\title{
Análise sobre a constituição de uma rede de Saúde Mental em uma cidade de grande porte
}

\author{
Analysis of the implementation of a Mental Health network \\ in a major city
}

Isabella Silva de Almeida (http://orcid.org/0000-0003-0929-8299) ${ }^{1}$

Gastão Wagner de Sousa Campos (https://orcid.org/0000-0001-5195-0215) ${ }^{2}$
${ }^{1}$ Faculdade de Saúde Pública, Universidade de São Paulo. Av. Dr. Arnaldo 715, Cerqueira César. 01246904 São Paulo SP Brasil. isa.bella.sa@hotmail.com

${ }^{2}$ Faculdade de Ciências Médicas, Universidade Estadual de Campinas. Campinas SP Brasil.

\begin{abstract}
This article set out to reflect on the setting up of psychosocial care networks based on the trajectory of a city in the greater São Paulo area. With that objective in mind, an exploratory study of the Unified Health System (SUS) and Mental Health in São Paulo between 1980 and 2013 was conducted. Official documents and articles, dissertations, theses and books concerning the implementation of the SUS in the city of São Paulo, with an emphasis on the mental health network, were analyzed. Open interviews with actors who lived through this moment in history were also conducted. In this manner, it was possible to highlight six important landmarks in this trajectory: the asylum-care model; the 1980s-advances and setbacks; 1989 to 1992 - the comprehensive care model for mental health; 1993 to 2000 - political setbacks and resistance; the 'Qualis II' Project; the municipalization of healthcare. Based on the analytical literature, the importance of historical events to understand the political proposals and the consolidation of public policies related to the SUS in São Paulo was revealed.
\end{abstract}

Key words Brazil's Unified Health System (SUS), Mental health, Psychiatric reform, Psychosocial care network
Resumo Este artigo se propôs a refletir sobre a constituição das redes de atenção psicossocial, a partir de um território do município de São Paulo. Para tanto, foi realizado um estudo exploratório sobre o SUS e a Saúde Mental no município no periodo de 1980 a 2013. Foram feitas leituras de documentos oficiais e artigos, dissertações, teses e livros sobre a implementação do SUS na cidade de São Paulo, com ênfase na rede de saúde mental. Realizou-se ainda a escuta de atores que viveram parte dessa história, a partir de entrevistas abertas. Dessa forma, foi possivel pontuar seis marcos: modelo assistencial asilar-manicomial; década de 1980: avanços e retrocessos; 1989 - 1992: modelo de atenção integral à Saúde Mental; 1993 - 2000: Retrocessos politicos e resistências; Projeto Qualis II; municipalização da saúde. Com essa leitura analítica, constatou-se a importância dos eventos históricos na compreensão das proposições políticas e na consolidação das políticas públicas, acerca do SUS São Paulo.

Palavras-chave Sistema Único de Saúde, Saúde mental, Reforma psiquiátrica, Rede de atenção psicossocial 


\section{Introdução}

A Saúde Pública no município de São Paulo (SP) tem um histórico de atravessamentos políticos partidários que, em muitos momentos, não estiveram de acordo com as políticas públicas nacionais. A constituição das Redes de Atenção Psicossocial (RAPS), o modelo de atenção à Saúde Mental, estiveram implicados a esse processo. Ao longo de cada gestão municipal diferentes investimentos foram feitos na Saúde Mental, ora mais pautado no modelo hospitalocêntrico, ora nas iniciativas privadas para sustentação da atenção em saúde, ora na atenção pública à saúde, de base territorial, articulada aos processos de vida e às relações estabelecidas pelas pessoas em sofrimento psíquico. Santos ${ }^{1}$, em relação aos espaços e territórios, aponta a necessidade de se compreender o processo histórico:

"O espaço deve ser considerado como uma totalidade, a exemplo da própria sociedade que lhe dá vida [...] o espaço deve ser considerado como um conjunto de funções e formas que se apresentam por processos do passado e do presente [...] o espaço se define como um conjunto de formas representativas de relações sociais do passado e do presente e por uma estrutura representada por relações sociais que se manifestam através de processos e funções"1.

Com esse pressuposto, o objetivo desse artigo é refletir sobre a constituição de uma das RAPS deste município, a partir de eventos históricos e das experiências vividas no território da Freguesia do Ó (FÓ)/ Brasilândia, situado na Coordenadoria de Saúde Norte (CRSN).

Dada as dimensões do município e multiplicidade de eventos, bem como pelo caráter vanguardista, e por vezes restrito, de algumas experiencias vividas tal recorte foi feito.

Esse artigo se justifica por propor leituras de alguns desses eventos na história da saúde mental no município de SP, e em especifico na FÓ/ Brasilândia. Eventos estes que possibilitaram reflexões sobre os arranjos feitos, sobre as forças que operaram em cada contexto, sobre as contribuições e tensionamentos nas políticas públicas municipais, estaduais e federais.

Essas reflexões fazem parte da pesquisa de mestrado sobre o Apoio Matricial dos CAPS à Atenção Básica, realizada nesta região de saúde no período de 2013 a 2015. Tal pesquisa foi aprovada por Comitê de Ética e desenvolvida de acordo com os preceitos éticos e respeito aos participantes.

\section{Métodos}

Foi realizado um estudo exploratório sobre a Saúde Mental no SUS no município de SP no período de 1980 a 2013 (Figura 1).

Foram realizadas 3 entrevistas com atores, aqui identificados como profissional 1, 2 e 3, cujo critério de inclusão foi o tempo de trabalho (maior que dez anos), implicação na construção da RAPS, ser referência para os serviços e demais profissionais da atenção (Quadro 1). As entrevistas eram abertas e foram áudio gravadas e transcritas, das quais foi possível construir uma narrativa ${ }^{2}$ sobre a constituição da RAPS. Todos os entrevistados assinaram Termo de consentimento Livre e Esclarecido.

Dialogou-se no macro e no micro, ou seja, das políticas públicas às práticas propostas $\mathrm{e}$ implantadas. O macro analisado a partir do material publicado em artigos, teses e dissertações, que nos possibilitou agrupar as reflexões em marcos, que para nós autores agrupou conceitos, arranjos e forças imprescindíveis para a compreensão da RAPS no território de saúde estudado. As entrevistas trouxeram as vivências no micro, nas práticas cotidianas, nas potencias e fabricações feitas pelo conjunto de gestores, trabalhadores, usuários e familiares.

A análise foi feita a partir do diálogo entre a história escrita e a história vivida, e dessa forma, não se pretendeu elucidar e descrever eventos, mas produzir algumas visibilidades.

O dialogo produzido foi organizado em seis marcos: Modelo assistencial asilar-manicomial; Década de 1980: avanços e retrocessos; 1989 1992: Modelo de atenção integral à Saúde Mental; 1993 - 2000: Retrocessos políticos e resistências; Projeto Qualis II; Municipalização da saúde.

\section{O modelo assistencial asilar - manicomial}

Historicamente, um primeiro olhar sobre a loucura, ao menos na identificação dos 'sujeitos desviantes' data do período colonial no Brasil, em uma sociedade ruralista, escravista, onde o Estado e a Igreja, controlavam os 'loucos', a partir da exclusão ${ }^{3}$.

De 1830 até a República, a classe médica se movimentou para que essa população pudesse receber tratamento à luz da psiquiatria, transformando a 'loucura' em doença mental, caracterizando uma mudança qualitativa na atenção ${ }^{4}$. São inauguradas 'Colônias' a fim de ofertar cuidado aos então considerados 'alienados'. 


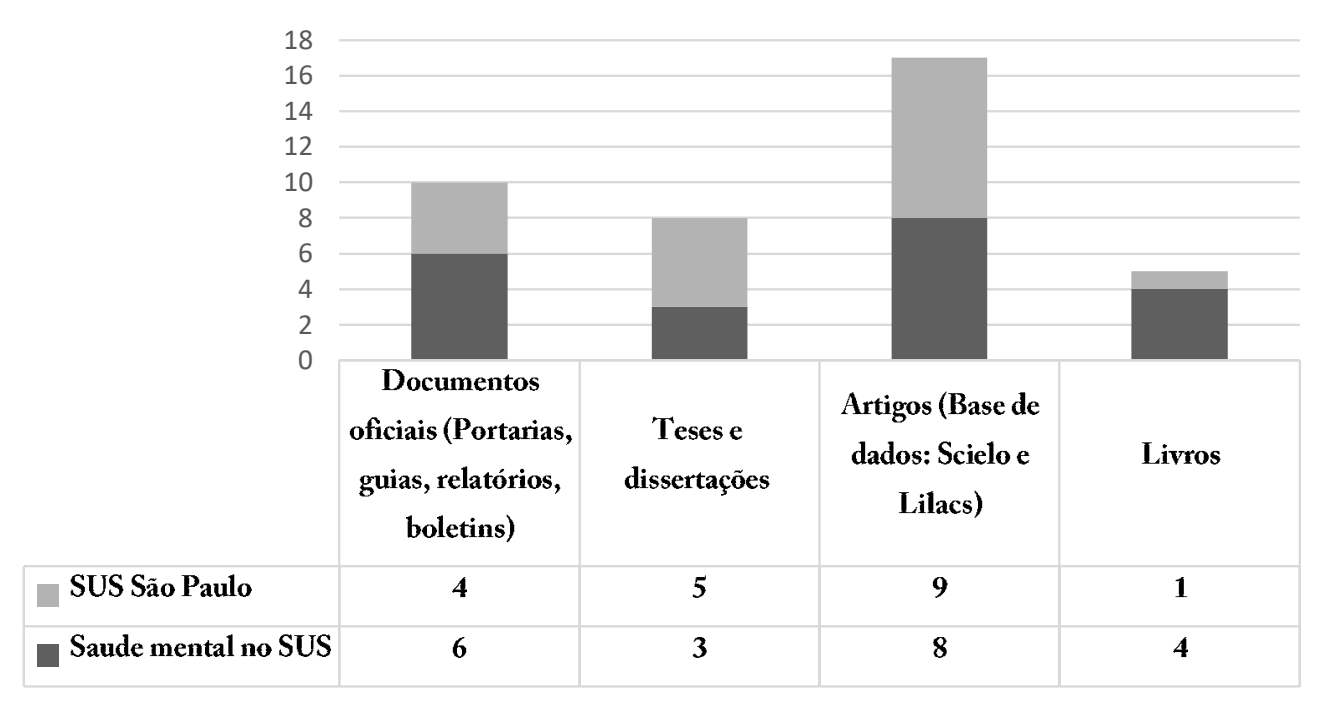

Saude mental no SUS

SUS São Paulo

Figura 1. Material utilizado para o estudo exploratório.

Quadro 1. Perfil dos profissionais entrevistados.

\begin{tabular}{|c|l|}
\hline $\begin{array}{c}\text { Profissional } \\
\text { Entrevistado }\end{array}$ & \multicolumn{1}{c|}{ Perfil } \\
\hline Profissional 1 & $\begin{array}{l}\text { Psicóloga. Inicia o projeto Qualis II em 1998, a partir de seleção em processo seletivo, } \\
\text { compondo a equipe de Saúde Mental, junto à Estratégia Saúde da Família na região. Após a } \\
\text { criação dos Núcleos de Apoio à Saúde da Família (NASF), em 2008, coordena algumas dessas } \\
\text { equipes na mesma região. No momento da pesquisa, mantinha-se nesta função. }\end{array}$ \\
\hline Profissional 2 & $\begin{array}{l}\text { Assistente Social, concursada desde 1988, chegou ao território da FÓ/ Brasilândia em } 1992 \\
\text { em uma Unidade Básica de Saúde (UBS). De 1995 a 2000, atuou na Administração Regional } \\
\text { de Saúde, retornando para a atenção à saúde em 2001. Em 2009 a partir da indicação dos } \\
\text { trabalhadores em Fórum, atua na articulação da saúde mental junto a então supervisão técnica } \\
\text { de Saúde (STS). No momento da pesquisa, estava como interlocutora de Saúde Mental. }\end{array}$ \\
\hline Profissional 3 3 & $\begin{array}{l}\text { Médico Psiquiatra, primeiro psiquiatra a integrar às equipes de Saúde Mental do Projeto } \\
\text { Qualis 2 em 1999/2000 na região. Em 2002 trabalhou na articulação de Saúde Mental } \\
\text { dessa região a convite da diretora do Distrito de Saúde da Brasilândia. Com a implantação } \\
\text { dos NASF, atuou como médico psiquiatra de uma das equipes. No momento da pesquisa, } \\
\text { compunha equipe de um dos serviços CAPS desse território. }\end{array}$ \\
\hline
\end{tabular}

Nas três primeiras décadas do século XX, a atenção se centrou nas 'Colônias', cuidado este pautado na segregação e na oferta de atividades laborativas. No Estado de SP, havia duas colônias importantes: Hospital e Colônias de Juqueri, em Franco da Rocha (criado em 1898, cujo nome mudou para este em 1929) e Sanatório Pinel, em Pirituba (Zona Norte do município de SP), sendo este de caráter privado entre 1929 e 1944, quando o governo do Estado de SP adquiriu o acervo social e mudou o nome para Hospital Psiquiátrico Pinel.

Nas décadas seguintes até 1960, ocorreu o aumento da população internada, superlotação das instituições e precarização da atenção. Ao mesmo tempo em que se ampliou os estudos e possibilidades de tratamento, como a eletroconvulsoterapia e a farmacoterapia, agregando novos 
interesses à Saúde Mental, como o da indústria farmacêutica e das instituições privadas de prestação de serviços de saúde.

A partir desse quadro e embasado pelo discurso da melhoria na atenção, o Instituto Nacional de Previdência Social fez convênios com a iniciativa privada, destinando quase a totalidade do recurso financeiro da saúde mental para a manutenção do aparato hospitalar público e, a partir da década de 1960, também do privado-conveniado (cerca de $90 \%$ da verba destinada à assistência psiquiátrica era gasta na compra de leitos de hospitais conveniados), contribuindo para o então chamado "rombo da Previdência"3,5 (Figura 2).

Na década de 1970, em meio ao Regime Militar, a conjuntura é de investimento no crescimento econômico do país que prevalece sobre os interesses sociais. Tal contexto agrava as condições gerais da população e faz emergir forças, movimentos pró reforma, pautados na luta por direitos. As políticas públicas para a atenção à saúde mental são questionadas; ideários progressistas reconhecem a necessidade de integração da Saúde Mental à Saúde Pública, ao mesmo tempo que se defendia o Hospital Psiquiátrico enquanto empresa privada ${ }^{6}$.

No Estado de SP, em 1973, a Coordenadoria de Saúde Mental da Secretaria Estadual de Saúde (SES) planejou uma nova assistência, que almejava proibir internações no Juqueri e criar prontossocorros para a atenção de curta duração, no en- tanto, não foi efetivada dada a disputa existente em manter o modelo hospitalocentrico vigente ${ }^{5}$.

Nesse contexto, trabalhadores, usuários e familiares se organizaram (Movimento dos Trabalhadores de Saúde Mental, Associações de Familiares e Usuários dos serviços), questionando as práticas da assistência psiquiátrica e discutindo sobre as instituições de saúde e seu papel na sociedade.

Em 1980, no Estado de SP, havia 121 hospitais psiquiátricos, sendo 112 particulares (41 sem fins lucrativos e 71 privados com caráter empresarial $)^{7}$ e uma incipiente rede de ambulatórios públicos (11), cuja proposta terapêutica restringiase ao tratamento psicofarmacológico e/ou oferta de guia para internação, sem integração técnica. Ou seja, um modelo de atenção pautado na atenção hospitalar.

\section{Década de 1980: avanços e retrocessos}

Na década de 1980, os movimentos reformistas - Sanitário e Psiquiátrico se fortaleceram e havia um sentimento nacional para o resgate do Estado de direitos e da cidadania, consoante com as perspectivas de redemocratização do país.

Alguns princípios nortearam a reorganização da atenção à saúde e da saúde mental, como $a$ universalização do atendimento, a descentralização das decisões, a regionalização da assistência e a integração e hierarquização dos serviços ${ }^{5}$.

\section{Número de Hospitais Psiquiatricos conveniados ao INAMPS}

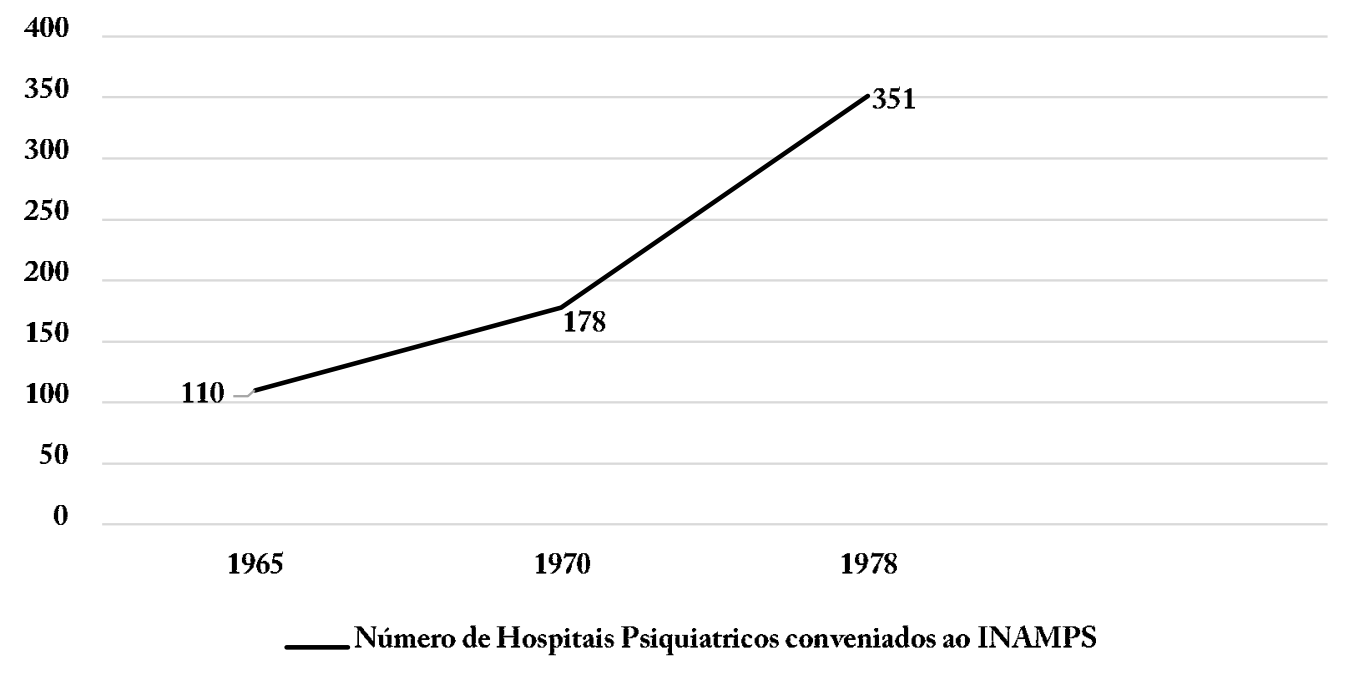

Figura 2. Hospitais Psiquiátricos conveniados 1965 - 1978. 
No estado de SP, aconteceu um Seminário de Saúde Mental, como parte dos preparativos do programa de governo de um dos candidatos e novas propostas em relação à Saúde Mental foram apontadas:

“[...] deveria ser implementada através de programas que contemplassem os três níveis primário, secundário e terciário - de atuação, se integrassem e regionalizassem, como forma de a médio prazo corrigir a distorção centrada na atenção terciária (hospitalocêntrica). Assim, o lugar prioritário seria a rede básica, a porta de entrada necessária para o atendimento"8.

Ao ser empossado em 1983, assume-se o compromisso de propor mudanças neste âmbito, sob influência do Plano de Reorientação da Assistência à Saúde da Previdência Social, o qual propunha o Programa das Ações Integradas de Saúde (PAIS), que preconizava a regionalização progressiva do sistema de saúde a ser coordenado pelas Secretarias Estaduais de Saúde (SES), de certo modo retoma-se o trabalho planejado em $1973^{6}$.

Assumido tal compromisso, a Coordenadoria de Saúde Mental passou a priorizar investimentos para a ampliação da rede extra-hospitalar, implantação de equipes multiprofissionais que dialogassem entre si, recuperação dos leitos próprios e melhoria na qualidade da assistência prestada pelos hospitais psiquiátricos.

Em consonância, no município de SP, foi proposto o "Projeto de Saúde Mental da Zona Nor-

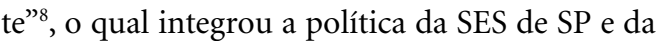
então Secretaria de Higiene e Saúde do município (SHS), a cadeira de Psiquiatria da Faculdade de Ciências Médicas da Santa Casa de Misericórdia de São Paulo (tinham um projeto docente-assistencial nesta região, fração reflexiva e analisadora do projeto) e o INAMPS (financiamento).

A área escolhida para implantação do projeto foi o Distrito Sanitário Nossa Senhora do Ó, com 585.000 habitantes (hoje compreende parte da área da Coordenadoria Regional de Saúde Norte - STS FÓ/ Brasilândia e STS Pirituba/Jaraguá), por contar com certo número inicial de equipamentos: Posto de Assistência Médica (gestão municipal) Carombé, Ladeira Rosa e Vila Penteado e o Centro de Saúde -1 Nossa Senhora do Ó (gestão estadual e com maior nível de complexidade na atenção). Nestes foram inseridas equipes de Saúde Mental, compostas por psiquiatra, assistente social e psicólogo, que contavam com a retaguarda do Ambulatório de Saúde Mental e com o Hospital Pinel, localizados em Pirituba.

No decorrer da gestão, ampliou-se o projeto para toda a Zona Norte (cerca de dois milhões de habitantes), aumentando o número de Centros de Saúde para 12 e integrando os cinco ambulatórios de saúde mental (Brasilândia, Mandaqui, Jaçanã, Lapa e Belenzinho). Foi criada uma Unidade de Emergência Psiquiátrica, com um serviço de resgate no Pronto Socorro Geral do Hospital do Mandaqui, o que representou um grande avanço na atenção às situações de crise em Saúde Mental.

Mesmo com as diferenças administrativas e organizacionais, como salários, áreas de cobertura e os momentos de cada gestão, havia uma proposição de integração de trabalho entre os governos estadual e municipal.

Para alicerçar esta mudança na lógica de atenção à saúde mental, elaboraram-se documentos para orientação das práticas cotidianas, como uso de medicamentos, rotinas de encaminhamento e processo de trabalho.

$\mathrm{O}$ projeto se preocupou também em construir um programa de Saúde Mental que dialogasse com o processo de adoecimento psíquico; prevenisse internações psiquiátricas desnecessárias; criasse procedimentos terapêuticos não cronificadores e abrisse espaço na rede pública de atendimento para a formação de profissionais especializados ${ }^{7}$.

Essa foi a primeira experiência documentada de uma atenção integrada e regionalizada em saúde mental no município, com importante engajamento dos atores envolvidos, com apoio político do governo do estado e de grande parte dos profissionais. Foi registrada uma efetiva ampliação da rede de atenção à saúde mental nos diversos níveis de atenção na região, o que de imediato refletiu na redução do número de internações psiquiátricas, além de propor outros modos de cuidado nos hospitais psiquiátricos ${ }^{8}$.

O cuidado em saúde mental, partiu de um trabalho em equipe co-responsabilizado, com mecanismos de referência e contra referência estruturados; reuniões técnicas e supervisão clínica instituídas. O projeto também fortaleceu os trabalhadores e o movimento de discussão sobre as políticas públicas em saúde mental.

Com a mudança na gestão municipal em 1986, não foi garantida a sustentabilidade do projeto; a SHS rompeu a parceria com a SES e iniciou a retirada de profissionais dos equipamentos do Estado.

$\mathrm{Na}$ gestão Estadual, iniciada em 1987, também houve um retrocesso no processo de reorganização da atenção à saúde mental, com o recadastramento de hospitais, reativação de convênios, retomada da lógica hospitalocêntrica e 
fomento a internação. Houve tentativas de fechar os Ambulatórios de Saúde Mental do município, como o da Brasilândia, impedida pela organização e luta de trabalhadores e usuários do serviço. Configurou-se, portanto, uma prática de desmonte do modelo que estava em construção.

Em 1985, ocorreu I Congresso de Trabalhadores de Saúde Mental, promovido pela Coordenadoria de Saúde Mental do Estado de São Paulo, marcando a reinvindicação dos trabalhadores de saúde mental enquanto atores no processo de mudança de atenção à saúde. Desse encontro, nasceu a Plenária de Trabalhadores de Saúde Mental, que atuou como elemento crítico e fórum de debates, discussões e propostas.

$\mathrm{Na}$ contramão destas mudanças políticas, em 1987, um grupo de trabalhadores da extinta Divisão de Ambulatório (SES) criou o primeiro Centro de Atenção Psicossocial (CAPS), 'Professor Luís da Rocha Cerqueira’ ou Itapeva, cuja proposta assistencial, distinta da hospitalização, foi formulada para atender os usuários dos serviços de saúde mental que apresentavam grave distúrbio psíquico e que demandavam tratamento intensivo ${ }^{5}$. Experiência singular que disparou muitas produções reflexivas no campo da Saúde Mental.

$\mathrm{Na}$ conjuntura nacional, em 1988, proclamou-se a nova constituição, a saúde é dever do Estado e de direito de todos. Aprovou-se o Sistema Único de Saúde, que foi regulamentado em 1990, com a Lei Orgânica da Saúde, Lei $8080 / 1990^{9}$.

\section{Modelo de atenção integral à Saúde Mental - PMSP (1989 - 1993)}

Nesse interim pós constituinte, iniciou-se uma nova gestão municipal em SP, considerada democrática e popular por diversos autores e estudos $3,6,10-12$.

Foi proposta uma reorganização administrativa do município, descentralizando a administração e garantindo autonomia às regiões na gestão. O município foi organizado em dez Administrações Regionais de Saúde (ARS) e 32 Distritos de Saúde, os quais seriam estratégicos para a organização e planejamento das ações a serem desenvolvidas no território a ele adscrito.

À luz do Movimento de Saúde Mental, a gestão desenvolveu um trabalho com intenções de alterar radicalmente o modelo hegemônico de atenção à saúde mental, propondo uma política intersetorial, que articulasse outros campos como assistência social, cultura, educação ${ }^{10}$.
O Plano Municipal foi embasado na compreensão da "saúde e doença como resultado do processo social"6. O planejamento das ações de saúde partiu das necessidades da população identificadas no regional/ local - Unidades e Distritos de Saúde, ou seja, almejou-se construir uma organização de serviços que atuasse sobre um território concreto, com problemas, cultura e gente concreta ${ }^{10}$.

As ações em saúde mental foram integradas à atenção em saúde e visavam à substituição do modelo manicomial. A proposta era construir uma rede substitutiva, consoante aos princípios do SUS (regionalização, integralidade das ações, ações de referência e contra referência, participação popular).

De acordo com documentos da SMS/SP ${ }^{3}$, o novo modelo de atenção em saúde mental tinha como alicerces:

"1. o combate à Cultura Manicomial presente nas instituições e na maioria da população;

2. a criação de um Modelo Assistencial em Saúde Mental, que tornasse desnecessária a internação psiquiátrica asilar;

3. o confronto político do poder público com a Instituição Psiquiátrica Manicomial e Asilar e seus subjacentes"3.

A Rede de Atenção Integral a Saúde Mental em cada região de saúde seria composta por UBS; Hospital Dia (HD); Centros de Convivência e Cooperativas (CECCO); Hospital Geral - Emergência de Saúde Mental, Enfermaria de Saúde Mental, interconsulta e psicologia hospitalar. Modelo de atenção similar ao proposto no "Projeto de Saúde Mental da Zona Norte” em 1983.

A intenção era potencializar e redirecionar as ações nos equipamentos de saúde já existentes, diversificar os espaços institucionais e dar amplitude as necessidades dos usuários, e desativar os Hospitais Psiquiátricos.

Cabe ressaltar que se tinha um sistema de saúde municipal incipiente, escasso e desconectado do sistema estadual, sucateado ${ }^{8}$. Houve, então, a necessidade de novos recursos humanos, financeiros e de criação de novos serviços.

Foi proposta uma política de formação que respondesse às necessidades do novo modelo de atenção. Investiu-se tanto em educação popular quanto na qualificação e formação dos profissionais. Foram contratados mais de mil novos trabalhadores em saúde mental, via concurso público.

Em 1992, tinha-se: 129 equipes multiprofissionais nas UBS com psicólogos, terapeutas ocupacionais e psiquiatras; 14 hospitais-dia (HD); 18 CECCO; 14 Emergências de Saúde Mental em Prontos Socorros Gerais, 3 enfermarias de saúde 
mental; 70 Equipes de saúde mental nos Hospitais Gerais Públicos; 06 Centros de Referência de Saúde do Trabalhador com ações de saúde mental.

Tanto as UBS quanto os serviços de emergência foram considerados como porta de entrada à rede de assistência. $\mathrm{O}$ tratamento se daria na UBS e no HD. A atenção à crise caberia aos equipamentos hospitalares, reorganizados para tal. A construção dos CECCO teve um caráter inovador, pela possibilidade de ações intersetoriais, integração de grupos populacionais marginalizados, enfrentamento de questões cotidianas referente aos mitos em torno da loucura e também pelo trabalho, através do resgate da economia popular por meio de cooperativas.

Os Lares Abrigados tinham a proposta de propiciar autonomia aos moradores, funcionando como um espaço intermediário entre a saída do paciente crônico do hospital psiquiátrico e sua reinserção social; no entanto, não foram implantados nessa gestão.

Houve um aumento significativo na população com problemas de saúde mental atendida no município: de 19.400 (1988) para 153.396 $(1992)^{10}$, com expressiva redução no número de internações, de 23.000 para 15.000 no mesmo período. Ainda que a necessidade do município fosse maior, esta gestão foi considerada um marco na organização dos serviços de saúde mental, conforme reafirmado por Scarcellí:

"A rede substitutiva paulistana, mesmo tendo se dado de forma incompleta, devido principalmente à reviravolta política (mudança de governo) em pleno processo de implantação, trouxe avanços no campo de atenção em saúde mental. Foi resultado de um longo processo de luta política pela democratização da sociedade brasileira, que vinha sendo travada por diferentes segmentos sociais, entre estes o Movimento Antimanicomial. A crítica construída ao aparato manicomial pôde finalmente penetrar no espaço institucional e, apesar de ainda não se configurar como uma concepção suficientemente elaborada, pode orientar grande parte das ações de trabalhadores e gerentes. Das críticas, elaboraram-se propostas e muitas delas traduziram-se em ações. Dentre as ações, muitas representaram a superação de antigas práticas do modelo psiquiátrico hegemônico. Parte delas foram apenas desconstruídas e outras não trouxeram inovação, simplesmente permaneceram. Deste contexto, novas problemáticas emergiram, seja no cotidiano do trabalho, seja na organização do movimento antimanicomial"6.

\section{3 - 2000: Retrocessos políticos e resistências}

Embora estivesse em construção um novo modelo de atenção em saúde mental, durante as gestões municipais de 1993 a 2000, não houve investimento na consolidação de tais práticas, não havendo continuidade à política de saúde mental antimanicomial.

Em 1995, implantou-se o Plano de Assistência à Saúde (PAS), inserido numa política de privatização da saúde pública municipal, justificado pela necessidade de se dar respostas imediatas às demandas da saúde.

"A absoluta maioria dos técnicos não aderiu ao sistema e optou por continuar na SMS; com isso sabiam que seriam transferidos dos postos de trabalho que haviam escolhido em 1992 e que não mais poderiam desenvolver trabalhos naquelas áreas, a partir da SMS”3.

$\mathrm{O}$ quadro de profissionais passou a ser composto por profissionais associados a cooperativas de trabalho, sem exigência de qualificação ou experiência na saúde pública. Também não havia uma política de formação dos profissionais. Reduziu-se número de serviços de saúde mental substitutivos aos manicômios, o número de profissionais atuando em saúde mental e consequentemente a população atendida ${ }^{10}$.

Durante o PAS os gastos orçamentários na saúde ficaram acima do previsto (cerca de $23 \%$ em 1996), todo o arranjo de descentralização administrativa e de recursos feitos na gestão anterior foram revertidos, com importante redução da autonomia dos Distritos de Saúde e dos trabalhadores, além do achatamento salarial destes, configurando um retrocesso na consolidação do SUS no município ${ }^{3}$.

A resistência se fez nas práticas cotidianas dos que permaneceram nos serviços de saúde, persistindo na garantia da atenção aos usuários; nas parcerias entre trabalhadores e usuários dos serviços e com o Movimento Popular de saúde, pela manutenção dos serviços e ações em saúde.

\section{Projeto QUALIS II (1998 - 2008) - SES}

Com a conjuntura municipal de desinvestimento no SUS e a opção da gestão por não se orientar pelas normas operacionais e legislações vigentes, criou-se um vazio em várias áreas de atendimento, inclusive na saúde mental.

Em 1996, por meio de uma parceria entre o governo do Estado de São Paulo, governo Federal 
e instituições privadas sem fins lucrativos, foi implantado no município o Programa de Saúde da Família (PSF). O projeto foi nomeado QUALIS (Qualidade Integral à Saúde). A primeira etapa - PSF QUALIS-I - se deu no Distrito de Saúde de Itaquera, situado na região leste do município. A segunda - PSF QUALIS II - foi implantada posteriormente nas regiões sudeste e norte.

Em 1998, foi implementado o Programa de Saúde Mental do Projeto, na região sudeste (Sapopemba) e Norte (Fó/Brasilândia, Casa Verde/ Cachoeirinha) de modo experimental. Estava alicerçado em duas estratégias: participação dos profissionais de saúde mental em reuniões com as Equipes de Saúde da Família para a escolha dos casos considerados mais graves e realização de atividades de sensibilização por meio de sociodrama.

Segundo Lancetti ${ }^{13}$, três ideias principais reforçavam esta proposição:

"A primeira era a de que a trama traçada pelo Projeto e suas conexões com os recursos da comunidade deveriam ser consideradas e ativadas em primeiro lugar. A segunda era a de que qualquer processo terapêutico consiste na ressignificação do sintoma, e que, para isso era preciso criar um dispositivo articulado à rede tecida pela organização de saúde. A terceira é que a invenção, e esse foi o tesouro que extraímos de todas as experiências vividas, deve fazer parte do método"13.

$\mathrm{Na}$ zona norte do município, inicialmente o projeto abrangeu três UBS da STS da FÓ/ Brasilândia (UBS Vila Penteado, UBS Dr. Augusto Leopoldo Ayrosa Galvão e UBS Vila Ramos) e duas da STS Casa Verde/ Cachoeirinha (UBS Ilza Hutzler e UBS Espanhola), havendo no total 22 equipes de saúde da família (Profissionais 1 e 2).

A equipe de Saúde Mental era composta por seis profissionais, que operavam como equipe volante, sem lugar fixo, sem salas para atendimento ou agenda. Foi adotada a organização de referência de saúde mental por Equipe de Saúde da Família. A referência era constituída por uma dupla, ou um trio de profissionais (psicólogos, assistentes sociais, terapeutas ocupacionais, psiquiatra).

[...] era um projeto inovador porque ele se propunha ter uma Equipe de Saúde Mental que dava apoio para a Equipe da Atenção Básica, e a Equipe da Atenção Básica trabalhando no formato da estratégia de Saúde da Família [...] o nosso objeto eram as famílias e não as patologias ou o indivíduo, e não tinha um espaço físico de atuação, então, a gente operava aonde a estratégia de Saúde da Família operava. (Profissional 3)
O processo de trabalho se constituía a partir de discussões de caso, construções de projetos terapêuticos, atendimentos compartilhados, visitas e atendimentos domiciliares. Ou seja, construiuse uma relação dialógica de apoio, com estratégias de cuidado e atenção ${ }^{13}$.

[...] foi construindo uma prática de visita domiciliar da saúde mental, foi construindo uma prática de como é que a gente faz contato com as famílias, no domicílio que é muito diferente do consultório, a clínica no território é uma clínica diferente da clínica do consultório, e com isso a gente também foi experimentando situações das mais diversas e a gente conseguiu acho que apesar da dificuldade algumas situações de matriciamento mesmo [...] (profissional 1)

A presença do Agente Comunitário de Saúde (ACS), o número de famílias adscritos a cada equipe associados à proposta do trabalho em equipe do PSF, favoreciam o compartilhamento das discussões e reflexões sobre as questões de saúde mental e ofereciam novas potencialidades para a construção de cuidados em saúde. Segundo Lancetti ${ }^{13}$, estas novas potencialidades estariam relacionadas ao fato do usuário ser procurado onde morava, priorizando o atendimento de necessidades e não apenas por demanda:

[...] nem sempre são atendidos os que mais necessitam, e mesmo pessoas em estado grave não procuram atendimento. No interstício da práxis se reforça o conceito de cidadania. As pessoas são atendidas por Direito e não por Demanda ${ }^{13}$.

Nessa construção, alguns espaços coletivos se organizaram e se fortaleceram, como o Fórum de Saúde Mental, que depois passou a ser denominado de Fórum dos Trabalhadores (espaço reflexivo e propositivo que se manteve até 2012), composto pelos trabalhadores da saúde Mental da rede. No qual,

[...] pode ir construindo um jeito de conversar, primeiro sobre a saúde, em cada unidade de saúde, sobre a lógica, que lógica é esta que a gente está fazendo, uma lógica mais voltada e condizente com as diretrizes do SUS ... Então a partir daí, a gente começou a pensar que os serviços de saúde como o Caps Adulto, por exemplo, o Ambulatório de Especialidades Maria Cecília, e o Ambulatório de Especialidades Fó, poderiam também funcionar como, com o matriciamento, então foi um trabalho gradativamente conquistado, porque os profissionais tinham muito medo... (profissional 1)

Esse espaço teve a estratégia de circulação pelos equipamentos de saúde, ou seja,

[...] esses fóruns eles começam no equipamento de saúde mental, mas depois há uma proposi- 
ção que eles sejam volantes, com a intenção de ir entrando em contato com cada unidade de saúde, com aquela região das unidades de saúde, ir contaminando por algumas vezes esses equipamentos e em outros fazendo uma espécie de invasão bárbara (profissional 3)

No município havia outras experiencias, com outros desenhos, propostas e parceria para execução.

\section{Municipalização da Saúde (2001)}

Em 2001, a saúde é municipalizada, ampliando-se o número de UBS/ PSF e experiências de Saúde mental na atenção básica, além da progressiva ampliação dos serviços substitutivos aos manicômios no município.

Com a lei federal 10.216/2001, ressaltou-se a importância da construção de uma rede de atenção que pensasse e realizasse o cuidado em saúde mental de modo ampliado e compartilhado, para além dos muros institucionais dos hospitais psiquiátricos.

Em fevereiro de 2002, a Portaria GM 336/02 orientou sobre a implantação dos CAPS, estabelecendo as modalidades, de acordo com a população do município, e as especificidades do público atendido ${ }^{14}$.

Propunha-se que o projeto terapêutico dos serviços fosse singular de acordo com as demandas. E o cuidado em Saúde Mental acontecesse onde a pessoa em sofrimento psíquico habitasse, circulasse e se relacionasse. A perspectiva era da oferta de um processo de reabilitação pautado no exercício pleno da cidadania e articulado ao potencial de contratualidade de cada indivíduo ${ }^{15}$.

Os então ambulatórios de Saúde Mental começaram a ser reestruturados a fim de se constituírem enquanto Centros de Atenção Psicossocial (CAPS). No território da FÓ/ Brasilândia, por exemplo, tal processo se iniciou entre 2001/ 2002,

[...] a gente passou muito tempo discutindo o papel do CAPS, a questão da porta do CAPS, esse foi o tema de muitos meses, e ai a gente se organi$z a$, a gente se dispõe a vir ajudar no acolhimento, a desmontar o ambulatório no sentido assim, ver quais os pacientes eram das unidades para devolver para as unidades, para apoiar as unidades para as unidades cuidar, e aí a organização vai saindo, que as unidades vão organizando duplas de Saúde mental, daquele fórum, de trabalhadores em formação e alguns que também não tinham formação mas se dispunham a tá junto, e ia ter cada unidade básica uma dupla de referência para receber e apoiar e pensar nas ações de Saúde Mental (Profissional 2)
Em 2004, eram 111 os CAPS no Estado de São Paulo, distribuídos nas distintas especificidades e modalidades ${ }^{13}$. No município há dados disponíveis a partir de 2009 quanto ao número de equipamentos CAPS, possuía 55, sendo 9 desses na CRS Norte ${ }^{16}$.

Em 2007, a SMS firmou contratos com Organizações Sociais de Saúde (OSS), instituições sem fins lucrativos, a fim de atuar em parceria na gestão dos serviços. Distintos cenários na organização da atenção à saúde passaram a existir nos territórios. Este modelo já havia sido vivenciado pela SES na gestão de hospitais e equipamentos de saúde, havendo diversas críticas em relação.

Em fins de 2008 e início de 2009, o município implantou equipes do NASF, de formação multiprofissional e composição estabelecida de acordo com as necessidades de cada território. $\mathrm{O}$ objetivo seria aumentar o escopo das ações em saúde das equipes de saúde da família, entre elas, desenvolver ações no campo da Saúde Mental, e integrar a RAPS no intuito de viabilizar e reforçar os processos de reinserção social ${ }^{17}$.

$\mathrm{Na}$ CRSN foram implantadas treze equipes do NASF, sendo cinco na STS da FÓ/Brasilândia. Desde então, as equipes de Saúde Mental do QUALIS e o arranjo feito pelos trabalhadores da rede para apoiar as UBS nas questões de saúde mental descrito anteriormente foram desfeitos.

Em 2009/2010, a partir de ação do Ministério Público, houve uma ampliação significativa da rede municipal de atenção em saúde mental (Figura 3), com o fechamento de Hospitais Psiquiátricos, abertura de novos CAPS, residências terapêuticas, unidades de acolhimento (de caráter transitório para usuários de álcool e outras drogas) e ampla discussão do fortalecimento dos CECCOs - Centro de Convivência e Cooperativa (que são em 21 estabelecimentos desde em $2009)^{18}$.

Outra intervenção que contribuiu para reflexões e mudanças na construção de redes de atenção, foi o apoio institucional proposto pela Política Nacional de Humanização (PNH)/ MS (2008) em alguns territórios do município.

À CRS Norte foi proposto o curso "Apoiadores Institucionais na Política Nacional de Humanização", que formou profissionais da rede. $\mathrm{Na}$ STS da FÓ/ Brasilândia, com o curso, organizouse o Grupo de Trabalho de Humanização (GTH), o qual foi fortalecido em 2010, com o apoio de consultores da PNH/MS. Como desdobramento das intervenções do GTH foi criado o Fórum de Redes, que reuniu tanto os serviços de saúde do território quanto os localizados fora dele, mas 


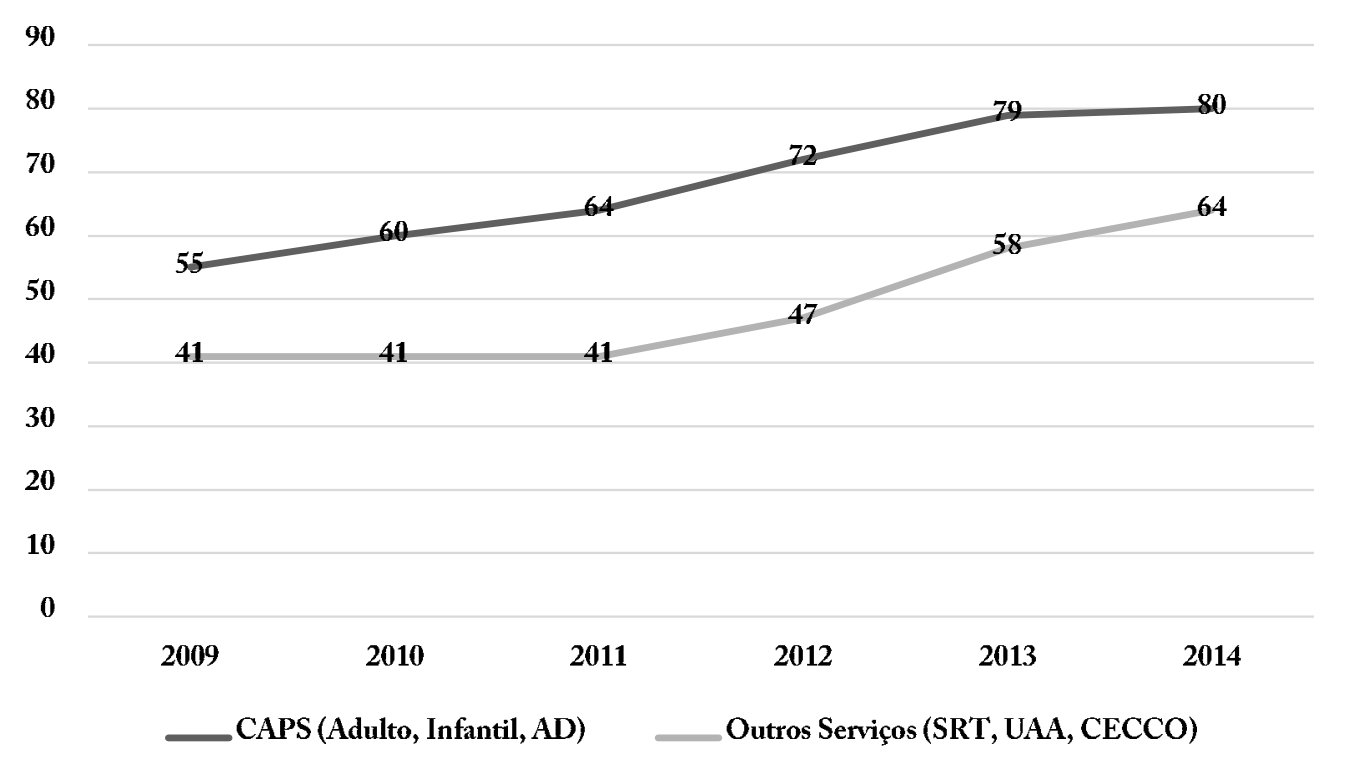

Figura 3. Serviços Saúde Mental do município 2009-2014. Fonte: Boletim CEInfo ${ }^{18}$

que eram referências para atendimentos aos usuários; o Grupo de Trabalho de Saúde Mental que teve como objetivo construir um Projeto Ético Político em Saúde Mental e o Grupo Gestor Fó com o objetivo de aproximar gestores da administração direta com gestores da OSS.

Tal estratégia consolidou novas grupalidades como espaços múltiplos de planejamento e acompanhamento das ações disparadas; estimulou o diálogo sobre as práticas de gestão em operação nas unidades e a construção de planos de intervenção para mudança das mesmas; aumentou o grau de implicação e co-responsabilização dos gerentes com processos de democratização das decisões e com projetos de articulação do sistema e de aquecimento da rede; promoveu aproximação dos conselheiros locais de saúde com as temáticas: gestão compartilhada, articulação dos serviços, princípios, métodos, diretrizes e dispositivos da PNH; formalizou o diálogo entre STS e gestores de OSS; apoiou no fortalecimento da articulação dos CAPS com as UBS, PS, AMAS ${ }^{19}$.

Em virtude dos contratos com as OSS criouse nova cultura institucional, com a quantificação dos procedimentos feitos e metas a serem atingidas pelos serviços (como número de cadastros abertos e atendidos / mês). Em contrapartida, houve movimentos de gestores locais, trabalhadores e usuários de resistência e diálogo com a gestão central (plenárias populares de saúde regionais, coletivos em prol da saúde mental entre outros).

Nesse processo, foram feitas discussões e ações na perspectiva de implantar os pontos de atenção da Rede de Atenção Psicossocial ${ }^{20}$ e consolidar a rede, que foi constituída por UBS, em sua grande maioria com ESF e apoiadas por equipes do NASF, um serviço CAPS II para a população adulta, um CAPS II infanto-juvenil, um CAPS III Álcool e Drogas com 8 leitos para acolhimento noturno, um CECCO, três SRT, duas Unidades de Acolhimento para Adultos mistas, um Pronto Socorro com leitos psiquiátricos.

Considerou esta ser uma rede com espaços coletivos vivos instituídos para trocas e reflexões.

\section{Considerações Finais}

Os eventos aqui descritos, a partir de uma perspectiva histórica, apontaram o quanto as mudanças políticas no município de SP interferiram na constituição do SUS e, consequentemente, em se ter uma atenção às questões de Saúde Mental consolidada. Há um ir e vir na proposição de projetos que desenham modelos de atenção e disputam uma política pública em Saúde Mental, no SUS de base territorial, centrada nas demandas e territórios de vida das pessoas em sofrimento 
psíquico. Há costuras, há resgates, há desconstruções, há reconstruções.

Os movimentos sociais, os trabalhadores, usuários e familiares foram propulsores e por vezes sustentaram as tentativas de consolidação de uma rede de atenção em Saúde Mental, tanto nesse território, quanto no município como um todo. Dos eventos aqui vistos, fica também que a garantia da cidadania, do Estado de direitos e do cuidado em liberdade se dá na práxis.

Nessa história ora o apoio dos gestores esteve mais presente e atrelado às mudanças positivas no funcionamento da saúde, ora a resistência de profissionais fez-se propulsora de transformações e reflexões necessárias para a consolidação do SUS e da RAPS no município.

No entanto, fica evidente que o município possui enormes desafios no tocante da Saúde
Mental/ SUS. Desafios esses que englobam tanto a diversidade dos territórios (modo de ocupação, cultura, aspectos econômicos, sociais etc.), o contingente populacional, quanto as estratégias adotadas a cada gestão municipal, sendo estas da ordem política, do planejamento, da gestão e dos modelos de atenção propostos.

As experiências que aqui se tornaram visíveis fabricaram territórios vivos e modos diferenciados de produzir saúde. Os projetos, de certo modo, puderam ser lidos enquanto meios de resistências diante dos interesses de mercado postos nas análises das políticas públicas. Há limites nas leituras feitas neste artigo, já que caberia aprofundar alguns eventos, como da cultura institucional instalada a partir dos contratos de gestão feitos pela SMS com as OS e a discussão sobre o atual cenário dos Hospitais Psiquiátricos.

\section{Colaboradores}

IS Almeida e GWS Campos contribuíram integralmente em todas as etapas de construção do artigo, ou seja, pesquisa, metodologia, concepção e redação final. 


\section{Referências}

1. Santos M. Por uma Geografia Nova. São Paulo: Hucitec, Edusp; 1978.

2. Onocko Campos RT, Furtado JP. Narrativas: utilização na pesquisa qualitativa em saúde. Rev Saude Publica 2008; 42(6):1090-1096.

3. Lopes RE. Cidadania, Políticas Públicas e Terapia Ocupacional, no contexto das ações de saúde mental e saúde da pessoa portadora de deficiência, no Município de São Paulo [tese] Campinas: Universidade Estadual de Campinas; 1999.

4. Amarante PDC. Loucos pela Vida: trajetória da reforma psiquiátrica no Brasil. Rio de Janeiro: Fiocruz; 1995.

5. Yasui S. CAPS: Aprendendo a perguntar. In: Lancetti A, organizador. SaúdeLoucura $n^{\circ} 1.2^{\text {a }}$ ed. São Paulo: Hucitec; 1989. p. 47-59.

6. Scarcelli RI. O Movimento Antimanicomial e a Rede Substitutiva em Saúde Mental: a experiência do município de São Paulo 1989 - 1992 [dissertação]. São Paulo: Universidade de São Paulo; 1998.

7. Cesarino AC, Santos DN, Macia EV, Reis HL, Dias IM, Leonel MLN, Goraieb R, Carvalho SGV. Projeto de ações Integradas de Saúde Mental na Zona Norte do Município de São Paulo: diretrizes gerais, conteúdo e configuração atual. Rev Ass Bras Psiq 1985; 7(27):131139.

8. Cesarino AC. Uma experiência de Saúde Mental. In: Lancetti A, organizador. SaúdeLoucura no 1. 2a ed. São Paulo: Hucitec; 1989. p. 3-32.

9. Brasil. Lei no 8.080, de 19 de Setembro de 1990. Dispõe sobre as condições para a promoção, proteção e recuperação da saúde, a organização e o funcionamento dos serviços correspondentes e dá outras providências. Diário Oficial da União 1990; 19 set.

10. Lopes IC. A contribuição Paulistana à Reforma em Saúde Mental Brasileira. In: Vieira MCT, Vicentin MCG, Fernandes MIA, organizadores. Tecendo a Rede: trajetórias da Saúde Mental em São Paulo 1989- 1992. São Paulo: Cabral Livraria e Editora Universitária; 2003. p. 29-91.

11. Oliver FC. Saúde Mental e Saúde da Pessoa com Deficiência: Estudo do Processo de Incorporação de Assistência pelos Serviços Municipais de Saúde numa Região do Município De São Paulo (1989-1995) [tese]. São Paulo: Universidade de São Paulo; 1998.

12. Nicanor RSP, Tanaka OU, Spedo SM. Política de saúde e gestão no processo de (re)construção do SUS em município de grande porte: um estudo de caso de São Paulo, Brasil. Cad de Saude Publica 2009; 25(4):927938.
13. Lancetti A. Saúde mental e saúde da família. In: Lancetti A, organizador. SaúdeLoucura $n^{\circ}$ 7. 2a ed. São Paulo: Hucitec; 2001.

14. Brasil. Ministério da Saúde (MS). Saúde mental no SUS: os centros de atenção psicossocial. Brasília: MS; 2004.

15. Pitta A. Reabilitação Psicossocial no Brasil. São Paulo: Hucitec; 2010.

16. Boletim CEInfo em Dados, $n^{\circ} 8$, outubro de 2009. [Acessado 2014 Nov 4] Disponível em: http://www. prefeitura.sp.gov.br/cidade/secretarias/upload/saude/ arquivos/publicacoes/BoletimCEInfoDados_2009. pdf

17. Brasil. Ministério da Saúde (MS). Portaria GM no 154 , de 24 de Janeiro de 2008. Cria os Núcleos de Apoio à Saúde da Família - NASF. Diário Oficial da União 2008; 04 Mar.

18. Boletim CEInfo em Dados. Ano XIII, no 13 , Junho de 2014 [acessado 2014 Nov 4] Disponível em: http:// www.prefeitura.sp.gov.br/cidade/secretarias/upload/ saude/arquivos/publicacoes/Boletim_CEInfo_Dados_2014.pdf

19. Haberland R, Ribeiro M, Ventura SM, Leal BMML, Almeida IS, Pavan C. Encontros, Transformações e Reencantamento - o GTH como coletivo disparador das reflexões/ações em Humanização. Pôster apresentado no I Fórum Paulista de Humanização, novembro, 2013.

20. Brasil. Ministério da Saúde (MS). Portaria GM no 3088, de 23 de dezembro de 2011. Institui a Rede de Atenção Psicossocial. Diário Oficial da União 2013; 21 maio.

Artigo apresentado em 13/09/2016

Aprovado em 17/10/2017

Versão final apresentada em 19/10/2017 